James Madison University JMU Scholarly Commons

Libraries

Libraries \& Educational Technologies

2013

\title{
Health sciences information literacy in CMS environments: learning from our peers
}

Tierney Lyons

Penn State Worthington Scranton

Stefanie Warlick

James Madison University

Follow this and additional works at: http://commons.lib.jmu.edu/letfspubs

Part of the Information Literacy Commons, and the Medical Education Commons

\section{Recommended Citation}

Lyons, T., \& Warlick, S. (2013). Health sciences information literacy in CMS environments: learning from our peers. Electronic Library, 31(6), 770-780. doi:10.1108/EL-06-2012-0063

This Article is brought to you for free and open access by the Libraries \& Educational Technologies at JMU Scholarly Commons. It has been accepted for inclusion in Libraries by an authorized administrator of JMU Scholarly Commons. For more information, please contact dc_admin@jmu.edu. 
EL

31,6

\section{0}

Received 8 June 2012

Revised 18 July 2012

Accepted 1 August 2012

\section{Health sciences information literacy in CMS environments: learning from our peers}

\author{
Tierney Lyons \\ University Libraries, Penn State Worthington Scranton, Dunmore, \\ Pennsylvania, USA, and \\ Stefanie Warlick \\ Rose Library, James Madison University, Harrisonburg, Virginia, USA
}

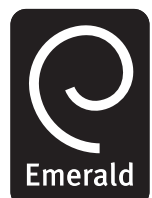

The Electronic Library Vol. 31 No. 6,2013 pp. $770-780$ (C) Emerald Group Publishing Limited 0264-0473

DOI 10.1108/EL-06-2012-0063

\begin{abstract}
Purpose - With academic institutions' adoption of Course/Learning Management Systems (CMS), librarians are increasingly providing content through this delivery method. This study aims to identify practical information for librarians considering CMS content development or re-evaluation of online offerings.

Design/methodology/approach - Academic libraries with health sciences information literacy programs within CMS were examined through a literature review and then queried through an online survey. Trends and issues identified within the literature were utilized to develop the survey. Collected data was analyzed to determine how librarians incorporate CMS into information literacy. Analysis focused on strategies used in development and delivery, benefits and challenges of CMS and pairing its content with traditional instruction methods.

Findings - An overarching theme is the ease and accessibility of CMS, especially for distance learners and those with time restrictions. However, although online tools and learning spaces are readily available and beneficial, librarians maintain in-person instruction. A shift from primarily positive published reports by early adopters to more constructive feedback that stems from longer-term CMS experience is identified. Assessment practices of online library instruction need additional attention to provide a more robust approach.

Originality/value - This unique examination of the last ten years of publications focusing on information literacy librarians' CMS activity is paired with a broad, updated examination of current trends. It identifies best practices related to time commitment, faculty relationships, and assessment for implementation in CMS environments and the importance of utilizing blended learning strategies.
\end{abstract}

Keywords Higher education, Information literacy, Academic health sciences, Blended learning, Course management

Paper type Research paper

\section{Introduction}

Technology options are often freely accessible, easy to use, and can be seamlessly integrated into the online learning environment that supports faculty and students. Currently, many colleges and universities provide virtual learning spaces via Course/Learning Management Systems (CMS), such as Blackboard, WebCT, and Moodle. These tools provide a secure, web-based classroom to administer, document, and assess educational content.

A first step to identifying best practices for integrating health sciences information literacy instruction in an online learning environment is examining library literature. 
Library and information science literature contains significant research on CMS, especially regarding integration of information literacy instruction. Prior surveys of traditional academic librarians identify information literacy approaches with CMS integration. These surveys provide insight into library experience with CMS, however, scant survey-based research is published regarding academic health sciences libraries' integration of information literacy instruction into CMS.

A search of the literature focused on academic libraries supporting health sciences disciplines was conducted in August 2010 and repeated in May 2011. LISTA, LISA, LLIS, ERIC, CINAHL, Nursing and Allied Health Source, and PubMed indexes were searched using keywords related to health and libraries, combined with any of the following phrases or terms: course management, learning management; blackboard; Moodle; angel; embedded librarian; or informationist. Articles that addressed the librarian roles in delivering CMS content were deemed relevant.

The twenty-one selected articles highlighted health science librarians' responsibilities and experiences in CMS content delivery in academic settings. The majority of the articles were case studies. Many demonstrated that library instruction content remained constant as delivery methods shifted (Jefkins, 2009; Hansen et al., 2009; De Leng et al., 2006). As instructors determined that students seem to respond better to multimedia rather than text-based materials, instruction format transitioned from predominantly text, such as documents and web pages, to interactive videos and some incorporation of audio. Information literacy instruction concepts such as search strategies, information evaluation, management of references, use of citation styles, and accessing sources, were moved from a traditional, in-person classroom environment to an online learning environment as new and improved education technologies emerged. Clearly, the popularity of posting content online has increased. Typically librarians report two reasons for this change. First, the use of blended instruction, a hybrid approach of in-person classroom sessions supplemented by CMS-based content, has increased. Second, librarians report an increase in online-only courses offered via CMS and some report that supporting these courses is the only available method of addressing the students' research skills needs (Guillot et al., 2010; Schutt and Hightower, 2009; Konieczny, 2010). To librarians' credit, they have been flexible with delivery methods thus demonstrating their commitment to reaching students at the point of need.

In some cases, health sciences libraries' CMS involvement extended beyond information literacy efforts. For example, CMS implementation (Lovett, 2004), continuing medical education (Brahmi and Hatfield, 2004), problem-based learning (De Leng et al., 2006), clinical experience (Hatfield and Bangert, 2005), and library staff training (Skhal and Thureson, 2007). Branching out to assist other departments establish and monitor CMS initiatives helped these libraries gain recognition as a resource in the new environment and potentially opened doors to the library incorporating its own resources and instructional content.

Overall, the literature cited many positive outcomes, including a perceived increase in the use of services and resources, increased collaboration with faculty, including building relevant assignments and integrating the library into their online sources (DaCosta and Jones, 2007; Dinwiddie and Winters, 2004). The case studies also pointed to the ease of use of this delivery method, especially for distance learners and students with time restrictions, needing self-paced instruction (Stone et al., 2004; Hansen et al., 
EL

31,6

772
2009). This venue offered an opportunity to reach distance students otherwise unreached. Interestingly, some who offered content via CMS saw increased requests for in-person meetings (Konieczny, 2010). Muir and Heller-Ross (2010) witnessed their CMS work reinforced partnerships with faculty, refocused their efforts on student learning, and established a continuous presence in the course throughout the semester. Florea (2008) also witnessed increased librarian/faculty and librarian/student collaboration as well as improved face-to-face content and teaching methods. Introducing new technology offered opportunities to examine teaching materials while increasing in-depth interaction with the classroom instructors.

Time intensity in using the CMS was consistently reported, especially in creating the content in the virtual format and, in some cases, administrating the course, due to an increase in reference transactions. Many see the need for increased course integration and service offerings that are more specific to assignments (Schroeder, 2010; Jefkins, 2009). The aforementioned integration would encourage more student communication within the online course.

Moving forward, libraries would like to see more librarian/student interactions (Lillard et al., 2009). Venues for this increased communication include discussion boards, chat, and interactive tutorials (Xiao, 2010). De Leng et al. (2006) point to the need for the discussion board postings being applied selectively and deliberately to foster in-depth discussion. Nearly all cases saw opportunity for more assessment of both student learning and effectiveness of the content and format. Florea (2008) states that the CMS features provided a good assessment avenue. Students appreciated the collaboration, interaction, peer feedback and multimedia use instead of text only (Cobus, 2009). Students learned from each other's postings and helped answer the questions of fellow classmates, which supported active learning processes. This pocket of literature depicts individual accounts of academic health science libraries CMS involvement. However, the following mixed methods study examines unreported work paired with the program descriptions found in the literature review to further assist librarians in making CMS instruction decisions.

\section{Research methodology}

This research consisted of two parts: a literature review and an online survey (see the Appendix). To focus the investigation, only academic libraries with medical, nursing, allied health, or general health sciences programs were targeted. First, the literature review was used not only as a way to gather information on what health sciences librarians are publishing related to CMS instruction, but also to develop questions for the survey and to enhance contextualization of survey results. Trends and issues found within the literature were utilized to develop the survey categories and questions. Second, the Institutional Review Board (IRB)-approved survey was administered as a means of gathering a more holistic perspective of the current practitioners' environment.

In Spring of 2011, the survey of health science librarians using CMS was conducted. The survey was distributed via medical library listservs, including chapters, sections, and regional library mailing lists. The invitation issued to the participants in the listserv postings linked to the survey. The cover letter included as the front page of the survey served as the consent form and explained potential benefits including an opportunity to reflect on information literacy strategies and being able to share data on experience with course management software with librarian colleagues. It also noted 
that participation was entirely voluntary and they could withdraw at any time. In addition to providing basic demographic information, participants were asked to report a scenario, a specific instruction content example that they have delivered for use in CMS, and answer 15 questions regarding teaching methods, tools used, and personal reflections in the context of the scenario they provided. To solicit more in-depth insights into librarian experiences and decision processes, half of the survey required open-ended responses rather than multiple-choice only. Survey responses were collected anonymously, but participants were given an opportunity to share contact information with the investigators for use in follow-up or data clarification.

Collected data was analyzed to determine how institutions have incorporated CMS into information literacy programs. Analysis focused on factors such as the content's interactive features and breadth of tools used, as well as pairing of electronic content with traditional instruction methods. Survey responses were analyzed in conjunction with the academic health sciences library literature findings.

\section{Research findings}

Of the 55 individuals who completed the survey, 40 of the respondents shared an instruction scenario that they were to use when responding to subsequent questions. Results presented in this section are based on those 40 responses. As part of the demographic inquiry, participants were asked which programs, schools, or departments they serve as well as to which levels (undergraduate or graduate/professional) they have provided CMS-based instruction. Participants were asked to check all that apply for each demographic question. The majority of respondents serve at least one graduate or professional level program, department, or school. Nursing was the most predominant discipline served followed by Medicine (Figure 1). Librarians choosing Allied Health were asked to specify the allied profession(s) served. Responses ranged from Medical Terminology to Exercise and Wellness to Physician Assistant. A variety of CMS tools were used by respondents, however, most reported Blackboard. Approximately a quarter of the participants reported use of more recent additions to the market, such as eCollege, Plateau, Sakai, and Desire2Learn. Of the 40 responses, five reported their institutions using the open source tool, Moodle.

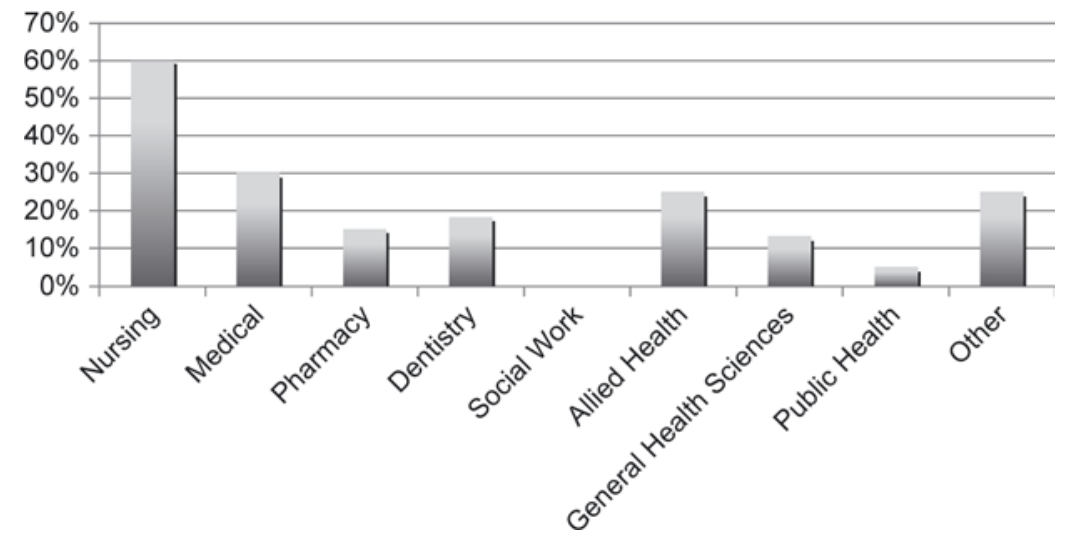

\section{Information literacy in CMS environments}

773
Figure 1.

Disciplines served $(n=40)$ 
EL

31,6

774

Content presented within the CMS instruction fell on a broad spectrum, with search strategies, evaluation of information, citation styles, and copyright most frequently cited. For questions related to the format of the instruction materials, respondents reported slideshows and text/HTML as most used, while video came next with audio reported the least (Figure 2). Several of those selecting the 'Other' category actually specified text format, such as PDF or Word documents, in their responses. These findings were consistent across undergraduate and graduate/professional level instruction. The most frequently used tools were slideshow software, word processing, screen casting, and followed by HTML (Figure 3).

Regarding time commitment for development of CMS content, responses were varied, but most reported spending a few hours to a week on the example provided in the specific scenario question. Time spent on maintenance differed by the amount of

Figure 2.

Format of instruction materials $(n=39)$
Figure 3.

Tools used $(n=38)$
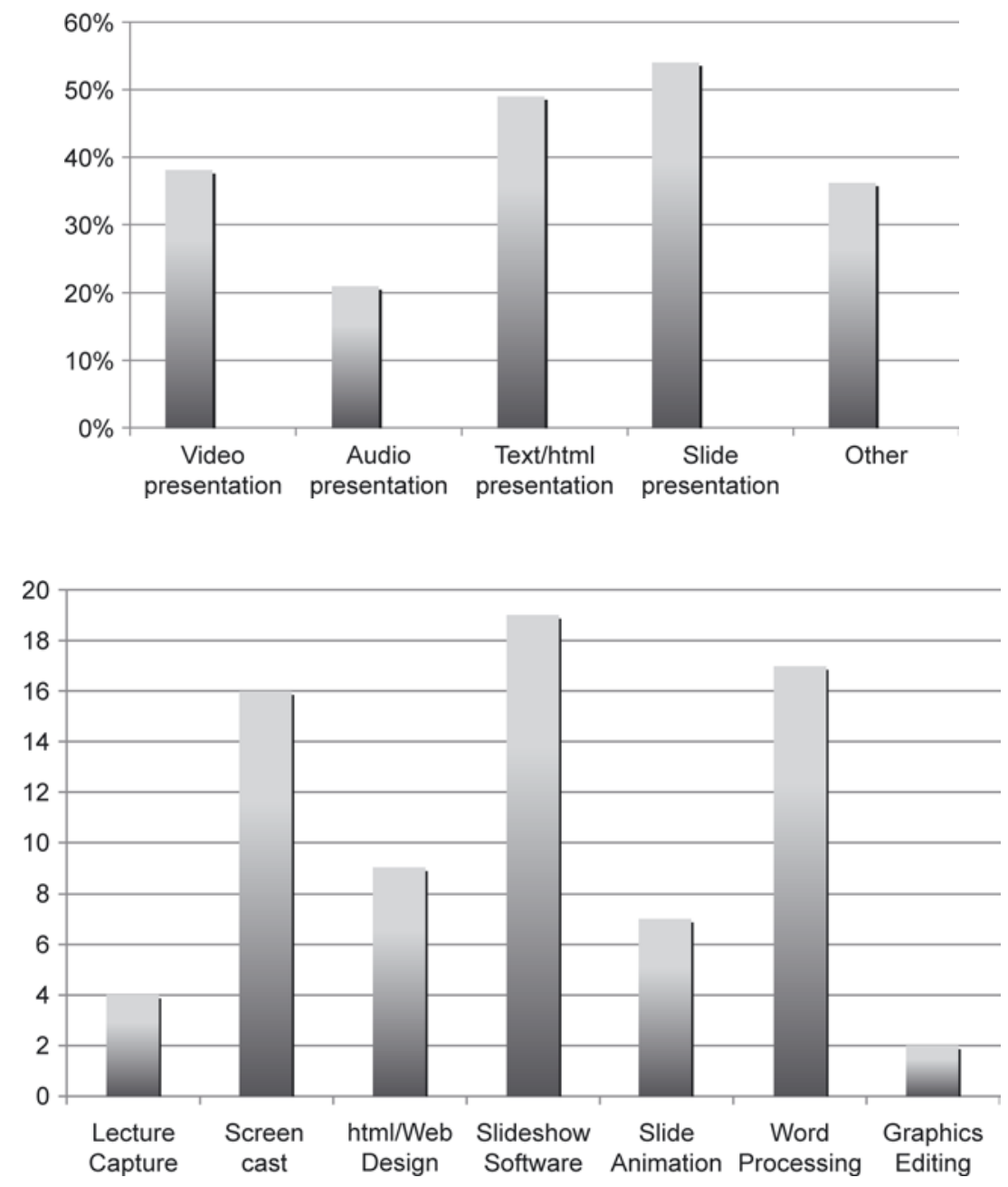
interaction with the students, with most attending to the instruction content weekly and second most about once a semester.

When asked how long it takes students to review or complete the instruction materials posted within the CMS, the majority reported time requirements of 60 minutes or less, with six of those reporting ten minutes or less. Others reported time requirement of multiple hours, sometimes spanning five or more weeks. Of the respondents, 77 percent indicated they would consider the type of instruction content as formal; 63 percent were engaged in blended instruction, as opposed to online only.

Participants reported communicating with students via email most often, but also through in-person interactions, using CMS discussion boards, and telephone calls. The largest number of participants reported using no assessment methods with the CMS content. Those that did incorporate assessment used these listed methods in order of popularity: evaluation form/survey; graded assignment; pre-test/post-test; frequent editing and review of content.

Toward the end of the questionnaire, participants were asked to reflect on their use of CMS for library instruction. When asked how to decide what content is appropriate for a CMS, the largest number noted course needs or student needs followed by specific faculty requests. When asked to report on overall impressions of the use of CMS for instruction, positive comments included that it is excellent for information literacy and the participation is measurable. Other positives were it is available on an as-needed basis, it is a familiar environment for students, and it is fairly easy for library instructors to learn. The drawback that students just skim or never open the content was noted. Advice to others included that instruction librarians should see the value of the CMS as a delivery method, especially when paired with in-person instruction, and to be willing to try new things. In addition, library instructors advised that one should allow enough time to do it right, make it interactive, and set reasonable expectations for time dedicated to communicating with the students. Themes noted across multiple open-ended questions were that a great deal of work is required on the front end compared to in-person instruction and that communication cues differ in an online environment. For example, it is difficult to determine if a student understood a concept, making some simple questions harder to answer. Another theme across the open-ended responses was regarding collaboration with faculty. Suggestions offered in the comments stated the important of faculty-librarian connections, such as it helps to have existing relationships, because it could be more challenging to build them in an online-only environment and that the content delivery relied on access to faculty space, thus making trusting relationships essential.

\section{Discussion of results}

An overarching theme in both the literature review and the survey results is the ease and accessibility of this delivery method, especially for distance learners and those with time restrictions. In addition, there is a tendency to pair CMS content with in-person instruction. Although online tools and learning spaces are readily available and the potential benefits are obvious, there is still a desire to maintain in-person instruction opportunities. In both the literature and the survey, it was noted that the instruction content and the format of instruction in a CMS environment is decidedly similar to in-person. Survey participants' commentary shows that assessment and gaining access to these learning environments pose both opportunities and challenges.

\section{Information literacy in CMS environments}

775 
EL

31,6

776

Furthermore, the creation of content and, in most cases, administration is more time consuming. When considering the development of instruction content for a CMS environment, it is important to consider the time commitment involved.

Anecdotal evidence gathered through the survey revealed that instructors have a generally positive perception of using CMS for providing content, but that formal assessment is needed to know if the learning outcomes are being reached. Participant responses and the literature review highlighted that many systems have built-in evaluation tools that could facilitate these assessment goals.

Data analysis shows that the scenarios and content provided by those reporting formal instruction were very similar to the informal scenarios. Participants clearly have varied opinions on what constitutes informal or formal instruction; some of the informal respondents still reported spending up to 40 hours on the creation and the majority required on going attention at least once a week. No obvious differences were found when analyzing data related to tools used, length of development time, and content between those providing instruction materials for undergraduates versus graduate students.

A number of themes were identified in the literature review, that were less apparent in the survey results. For example, benefits of CMS delivery cited in the literature included an opportunity for more assignment-specific instruction and an increased use of library services or in-person interaction with the librarian. In some cases, the literature and the survey results show a discrepancy. In one instance, some of the published cases reported increased faculty collaboration, whereas the survey results, in addition to mentioning this benefit, highlighted this technology as a potential barrier to collaboration. In a similar vein, the literature review mentions leveraging opportunities for more communication while the survey results suggest that, due to the ease and accessibility of communication in an online setting, librarians should be careful when setting expectations and be thoughtful of how it will impact their time commitment.

\section{Conclusions}

Findings from the literature review and survey results augmented the authors' notions about current CMS library presence and confirmed the benefit of learning from peers' experiences before undertaking a comprehensive CMS project. The specific knowledge gained through this exploration is a combination of best practices that should be implemented in a CMS environment and ideas for methodologies that might prove successful with local populations. Take away messages include the importance of implementing a thoughtful strategy regarding time commitment and organization to accomplish initial content development and address on-going maintenance and communication expectations. Also stressed is the significance of the faculty/librarian relationship. This collaboration is essential for not only gaining admission to the online space, but also for truly leveraging this new kind of course "access" through meaningful assignment-level integration and targeted student/librarian interactions. It also facilitates assessment, which is key in determining the efficacy and benefits of CMS content delivery. Possibly the clearest theme that arose from this investigation was that, if possible, librarians should take a hybrid or blended approach to maintain the valued in-person interaction with students and faculty.

The length of survey and large number of open-ended questions likely resulted in a relatively low response rate. In addition, many of the survey respondents who completed 
the survey did not respond to each of the questions. As noted earlier, the nature of the study makes it difficult to explore the research questions without surveying colleagues or administering time-intensive interviews. In future studies, it will also be important to account for individual differences when considering concepts such as informal versus formal, tools versus format, and time required for content development. For example, while time required for content development was captured through survey questions, participant comfort level with the tools they were using was not measured. There was no differentiation between first-time CMS content creators and those with experience or robust technological support. Knowledge of participant comfort level would help clarify how time was spent: learning the tool or simply developing the content.

As is typical with many research projects, this investigation has led the authors to ask questions that require further exploration. Results revealed that when developing materials for a CMS environment, librarians are often duplicating content that was previously presented during in-person instruction. In the context of the known benefits a hybrid approach offers to information literacy instruction, the authors are very interested in exploring the relationship between CMS content/online interaction with students and traditional instruction content/in-person student interactions. Specifically, discovering a formula that leverages the benefits of both CMS delivery and traditional instruction would increase instruction librarians' information literacy impact.

One of the advantages of using CMS is the built-in assessment tools that measure participation and allow for instant feedback. Moving forward, learning how to best utilize these tools to implement an assessment plan will expedite librarians' evaluation objectives. Perusing the broader higher education literature can lay the foundation for achieving these goals for improving online library instruction.

A theme thorough this research was the potential for higher-level interactivity among librarians, students, and faculty. Evidence in this study shows that librarians see the need for such online collaboration and should strive to maximize the CMS communication functionality to exploit this feature. A future exploration of web-based academic information literacy activities and techniques will uncover means of increasing interaction with students and course integration.

\section{References}

Brahmi, F.A. and Hatfield, A.J. (2004), "Angel: post-implementation evaluation at the Indiana University School of Medicine”, Medical Reference Services Quarterly, Vol. 23 No. 3, pp. $1-15$.

Cobus, L. (2009), "Using blogs and wikis in a graduate public health course", Medical Reference Services Quarterly, Vol. 28 No. 1, pp. 22-32.

DaCosta, J.W. and Jones, B. (2007), "Developing students' information and research skills via blackboard", Communications in Information Literacy, Vol. 1 No. 1, pp. 16-25.

De Leng, B.A., Dolmans, D.H., Muijtjens, A.M. and van der Vleuten, C.P. (2006), "Student perceptions of a virtual learning environment for a problem-based learning undergraduate medical curriculum”, Medical Education, Vol. 40 No. 6, pp. 568-575.

Dinwiddie, M. and Winters, J. (2004), "Two-stepping with technology: an instructor/librarian collaboration in health promotion for baccalaureate nursing students", Journal of Library and Information Services in Distance Learning, Vol. 1 No. 4, pp. 33-45.

Florea, M. (2008), "Using WebCT Wiki Spaces, and ePortfolios for teaching and building information literacy skills", Journal of Library Administration, Vol. 48 Nos 3/4, pp. 411-430.

\section{Information literacy in CMS environments}

777 
EL

31,6

778
Guillot, L., Stahr, B. and Meeker, B. (2010), "Nursing faculty collaborate with embedded librarians to serve online graduate students in a consortium setting", Journal of Library and Information Services in Distance Learning, Vol. 4 Nos 1-2, pp. 53-62.

Hansen, E., Clark, C., McCleish, J., Hogan, J., Schutt, M., Hightower, B. and Xiao, J. (2009), "Getting to know you: development of an RN-to-BSN online orientation", Journal of Nursing Education, Vol. 48 No. 11, pp. 638-641.

Hatfield, A.J. and Bangert, M.P. (2005), "Implementation of the clinical encounters tracking system at the Indiana University School of Medicine", Medical Reference Services Quarterly, Vol. 24 No. 4, pp. 41-58.

Jefkins, A. (2009), "UCL subject librarians get WISE in moodle", SCONUL Focus, Vol. 45, pp. 45-77.

Konieczny, A. (2010), "Experiences as an embedded librarian in online courses", Medical Reference Services Quarterly, Vol. 29 No. 1, pp. 47-57.

Lillard, L., Norwood, S., Wise, K., Brooks, J. and Kitts, R. (2009), "Embedded librarians: MLS students as apprentice librarians in online courses", Journal of Library Administration, Vol. 49 Nos 1/2, pp. 11-22.

Lovett, D.G. (2004), "Library involvement in the implementation of a course management system”, Medical Reference Services Quarterly, Vol. 23 No. 1, pp. 1-11.

Muir, G. and Heller-Ross, H. (2010), "Is embedded librarianship right for your institution?", Public Services Quarterly, Vol. 6 Nos 2/3, pp. 92-109.

Schroeder, H. (2010), “Creating library tutorials for nursing students”, Medical Reference Services Quarterly, Vol. 29 No. 2, pp. 109-120.

Schutt, M.A. and Hightower, B. (2009), "Enhancing RN-to-BSN students' information literacy skills through the use of instructional technology", Journal of Nursing Education, Vol. 48 No. 2, pp. 101-105.

Skhal, K.J. and Thureson, C. (2007), "ICONic training: use of a course management system to provide continual reference student education”, Medical Reference Services Quarterly, Vol. 26 No. 2, pp. 15-25.

Stone, V.L., Bongiorno, R., Hinegardner, P.C. and Williams, M.A. (2004), "Delivery of web-based instruction using blackboard: a collaborative project", Journal of the Medical Library Association, Vol. 92 No. 3, pp. 375-377.

Xiao, J. (2010), "Integrating information literacy into Blackboard Librarian-faculty collaboration for successful student learning”, Library Management, Vol. 31 No. 8, pp. 654-668.

\section{About the authors}

Tierney Lyons is Reference Librarianat Penn State Worthington Scranton in Dunmore, Pennsylvania, USA. Prior to this role, Tierney served as the Head of Reference Services at the University of Maryland Baltimore Health Sciences Library. She received a Master of Library \& Information Science from San Jose State University. Her current research interests are print and electronic collections conservation and access, evidence-based practice instruction, and libraries' visibility and relevance in the digital age. Tierney Lyons is the corresponding author and can be contacted at: txl133@psu.edu

Stefanie Warlick is Assistant Director and Learning Commons Coordinator of the Rose Library at James Madison University (JMU). Before taking on this role in 2011, Stefanie worked at JMU as the Health \& Human Services Liaison Librarian. Stefanie obtained her MSLS from the University of North Carolina at Chapel Hill. Her current research interests are library instruction, user-centered learning spaces, and library leadership. 
Appendix. Online survey on librarians' use of course management systems

1. Do you support any programs, schools, or departments with Course Management (CMS) or Learning Management Systems (LMS) based instruction?

Yes

No

2. What programs, schools, or departments do you support with CMS/LMS based instruction? (check all that apply)
Nursing
Medical
Pharmacy
Dentistry
Allied Health (please specify)
General Health Sciences
Public Health
Other (please specify)

3. Which levels do you support with CMS/LMS-based instruction? (check all that apply)

Undergraduate

Graduate/Professional

Other (please specify)

4. What CMS/LMS do you use?

Blackboard

WebCT

Angel

Other (please specify)

5. As you answer the following questions, please think of a specific instruction content example you developed for use in a CMS/LMS. This example can be the one which you are most proud, the one most heavily used, one you think would be interesting to share, or simply one you are comfortable describing. Feel free to use a past or current example. Briefly describe the example you have in mind below.

6. In what format was your content delivered? (check all that apply)

Video presentation

Audio presentation

Text/html presentation

Slide presentation

Other (please specify)

7. What tools did you use to create the content for the CMS/LMS? Briefly describe below.

8. How long did you spend creating the content? (Approximate \# of hours)

(continued)

\section{Information literacy in CMS environments}


$\mathrm{EL}$

31,6

\section{0}

Figure A1.
9. Once the content was posted, how would you characterize the demand on your time?

Required attention at least once a week

Required attention at least once a month

Required attention at least once a semester

Required attention at least once a year

10. If you were to describe the content to a colleague, would you describe it as formal or informal instruction?

\section{Formal}

Informal

11. What type of information literacy information did you cover within this example? For example, did the content cover search strategies, evaluation of information, citation methods, copyright or another information literacy topic?

12. What is your impression of the amount of time it takes students to review/complete your CMS/LMS content? (Fill-in approximate amount)

13. How did you communicate with students using the CMS/LMS-based instruction? (check all that apply)

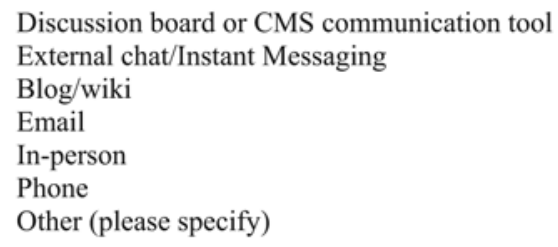

14. Were traditional instruction methods, such as in-person classroom instruction and research consultations, used in conjunction with the CMS/LMS-based instruction?

$$
\text { Yes }
$$$$
\text { No }
$$

15. Did you assess/evaluate the content? If so, please describe below.

16. What were your general impressions of using CMS/LMS to deliver your information literacy instruction?

17. Have you provided instruction for courses that your institution offered as distance education only? If so, was the instruction CMS/LMS-based?

Yes, but not offered within CMS/LMS

Yes, offered within CMS/LMS

No

18. In general, outside of your example, how do you decide if your information literacy content is appropriate for CMS/LMS?

19. What advice would you give to other librarians considering CMS/LMS as an instruction delivery method?

20. Feel free to include any additional information you would like to share regarding your CMS/LMS-based Information Literacy efforts below. 